\title{
correspondence
}

\section{Spoon bending: an experimental approach}

SIR,-We have investigated six young people who claimed the power of bending objects by stroking in the manner demonstrated on television recently by Uri Geller and others. In this report we will call these people A, B, C, D, E, and F. A, B, and F are young girls all aged eleven years. $C$ is a girl of thirteen, while $\mathrm{D}$ and $\mathrm{E}$ are boys aged ten and eight respectively. All were contacted with the aid of local press and television. A, B and C had received publicity in the local evening papers. Subsequently Dr Pamplin appeared on BBC "Points West" local television news programme when $\mathrm{B}$ demonstrated her ability quite convincingly. The parents of $\mathrm{D}, \mathrm{E}$ and F subsequently contacted Dr Pamplin claiming that their children could also bend cutlery by stroking.

Most of the subjects were first visited in their own homes where they showed their ability in the casual atmosphere of their sitting rooms. A succeeded in bending a weighed and measured rod of mild steel of $3 / 10$ ths inch diameter supplied by the experimenters as well as her own cutlery.

All six subjects were subsequently tested in Bath University's psychology laboratory. This laboratory has three large one-way mirrors behind which the experimenter can observe, photograph and take television video tape unseen by the subject. In all cases, except A, one or more observers sat in the laboratory with the subject. In the first four experiments there was a second television camera in the laboratory with the observers. The subject was handed the spoon or rod after its outline had been drawn on a sheet of paper and was allowed to stroke it in the approved manner between forefinger and thumb of one hand and to report what they felt was happening. $B$ reported that the spoon "felt soft" before bending. C stated that it "felt like plaster, then running water". The running water feeling occurred, it was said, just before bending occurred. However, at no time did $\mathrm{C}$ bend anything for us while experimenters were watching. The others all succeeded in bending spoons and $\mathrm{B}$ bent a rod of mild steel as well.

The aim of the experiment was to obtain a photographic or video taped record of the actual moment of bending. The observer in the room measured the spoon against its outline at intervals during the session noting the time.

The observers in the room were instructed to deliberately relax their vigilance at intervals after the first twenty minutes. The experimenters were specially alert during these periods and in all cases except $\mathrm{C}$ they observed and photographed cheating by the subjects. $A$ put the rod under her foot to bend it; $\mathrm{B}, \mathrm{E}$ and $\mathrm{F}$ used two hands to bend the spoon using considerable muscular power, while D tried to hide his hands under a table to bend a spoon in both hands out of sight of the observer.

We can assert that in no case did we observe a rod or spoon bent other than by palpably normal means. We cannot, of course, conclude that all instances of the so called Geller Effect are due to cheating. However we offer details of our experimental procedure in the hope of helping other experimenters design experiments that can be used when cheating is suspected.

$$
\begin{aligned}
& \text { Dr Brian R. Pamplin } \\
& \text { Mr Harry Collins }
\end{aligned}
$$

Bath University, UK

\section{Presto! Would you believe?}

SIR,-In his review of John Taylor's book, "Superminds", Dr C. Evans comments on the ease with which the author seems able to discount the possibility of fraud and deceit on the part of the children involved in purported "psychic" performances. I recently launched an experiment with a newspaper which reports psychic phenomena to prove that persons lacking expertise can easily be deceived by a person using very simple methods-if the predisposition to belief is there. I am a professional conjuror, and needed only modest skills to convince the newspaper that I was indeed possessed of very strong paranormal abilities. It was only necessary to claim genuine powers for the observer to relax completely and believe all.

The need to have a competent conjuror present at performances of this nature is very evident. Otherwise, the observations are of no value scientifically.

51 Lennox Avenue,

JAMES RANDI

Rumson,

New Jersey

\section{Publishing problems}

SIR,-I wish to draw your attention to the difficulties which Czechoslovakian scientists seem to be encountering when publishing in international journals.

From a letter which I received from one of our contributors I learn that a paper sent to him arrived in Prague on April 7, 1975, but the author did not receive it until May 23, 1975. Furthermore, he was "commanded out" of Prague on May 24 for two weeks.

I am wondering what these ominous words "commanded out" actually mean. As fellow scientists, we have all been deeply conscious of the treatment received by some of our colleagues in Russia, who have been "frozen out" or even interned.

Let us hope that the Czechoslovakian government will not resort to Soviet methods and will continue to allow their talented scientists to publish in international journals.

Jorgen Clausen

Neurobiology,

Copenhagen, Denmark

\section{Additive safety}

SIR,- "We tend to trust Mother Nature, and suspect the organic chemist", says Thomas Jukes mockingly in his vivid defence of synthetic food additives August 7. There is, of course, a reason to trust natural food better than food additives which must be familiar to the author of Molecules and Evolution: Organic chemistry happens to be 147 years old; man is at least $1 \times 10^{6}$ years old, and has thus fed for 999,853 years on natural food. The fact that man has survived all these effects of "numerous chemicals (in natural food) that are all more or less toxic" does not prove at all that there will be some fittest to survive the ingestion of at least as many food additives introduced mostly in the past 10-20 years.

Indeed, we do not know whether sodium benzoate has some disagreeable effects within 3 or 10 generations, whereas sugar ("one of the most ancient and universal of food preservatives") has passed the most rigorous toxicological test there is: time. Besides, sugar tastes better.

\section{R. E. Humbel}

University of Zïrich, Switzerland 